\title{
Facial rash with scarring due to granulomatous vasculitis in rheumatoid disease
}

\author{
RAYMOND WHITE, ${ }^{1}$ ANNETTE WEGMAN ${ }^{2}$ PETER BULPITT ${ }^{3}$ \\ GLENDA WOOD, AND ANTHONY FLEMING ${ }^{1}$
}

From the Departments of ${ }^{1}$ Rheumatology, ${ }^{2}$ Dermatology, and ${ }^{3}$ Pathology, Prince Henry and Prince of Wales Hospital Group, Sydney, Australia

SUMmaRY A 60-year-old man with destructive rheumatoid disease, multiple nodules, and vasculitis developed a facial rash with ulceration and scarring. Histology showed granulomatous vasculitis. The rash was rapidly controlled with oral corticosteroids. Granulomatous vasculitis has not previously been reported as causing this clinical picture in the absence of concomitant necrobiosis and palisading.

Key words: rheumatoid arthritis, granuloma, nodules.

The skin manifestations of rheumatoid disease are multiple and well described. ${ }^{1}$ They include vasculitic skin infarcts, ${ }^{2}$ nail fold lesions, ${ }^{1}$ pyoderma gangrenosum, ${ }^{3}$ leg ulcers, ${ }^{4}$ extravascular necrotising granuloma (Churg-Strauss), ${ }^{5}$ and rheumatoid nodules with or without superficial ulceration. ${ }^{6} \mathrm{~A}$ rare occurrence is that of an ulcerating lesion with histological evidence of granulomatous vasculitis but showing also evidence of rheumatoid nodule formation. $^{78}$

We describe a clinically similar ulcerating rash where scarring, however, was more prominent. Furthermore, although a granulomatous vasculitis was obvious, no histological evidence of the classical features of the rheumatoid nodule was noted, including necrobiosis, fibrinoid necrosis, or palisading. This finding may have implications in our understanding of the mechanism of rheumatoid nodule formation.

\section{Case report}

A 60-year-old man was admitted with a facial rash.

Accepted for publication 18 June 1985.

Correspondence to Dr A Fleming, Department of Rheumatology. Prince Henry Hospital, Little Bay, Sydney, NSW 2036, Australia.
He had a 15-year history of seropositive, erosive, nodular, progressive, and deforming rheumatoid arthritis. Treatment in the past had included Dpenicillamine and cyclophosphamide. A feature of his disease had been the extra-articular manifestations of heavy rheumatoid nodularity, recurrent leg ulcers, and vasculitis, including small skin infarcts and nail fold lesions.

The facial rash had commenced 10 months before admission in the right preauricular area and had extended to involve his right cheek, spreading forward to his chin, right forehead, and right side of the neck. The rash was erythematous, ulcerating, crusted, with raised edges, and resulted in scarring (Fig. 1). There was a small area with similar appearance on the right upper arm. Physical examination at the time showed the stigmata of deforming rheumatoid arthritis, multiple nodules, and leg ulcers. There were small bilateral pleural effusions but no other extra-articular features.

Investigations showed $\mathrm{Hb} 148 \mathrm{~g} / \mathrm{l}$, white cell count $8.2 \times 10^{9} / 1$, erythrocyte sedimentation rate 47 $\mathrm{mm} / 1 \mathrm{st} \mathrm{h}$, Rose-Waaler titre $1 / 1024$, and ANA titre $1 / 400$ to peripheral blood neutrophils. Antibodies to DNA were not detected by Crithidia luciliae or counterimmunoelectrophoresis, and the Farr assay was normal at $16 \%$. Immune complexes were raised 


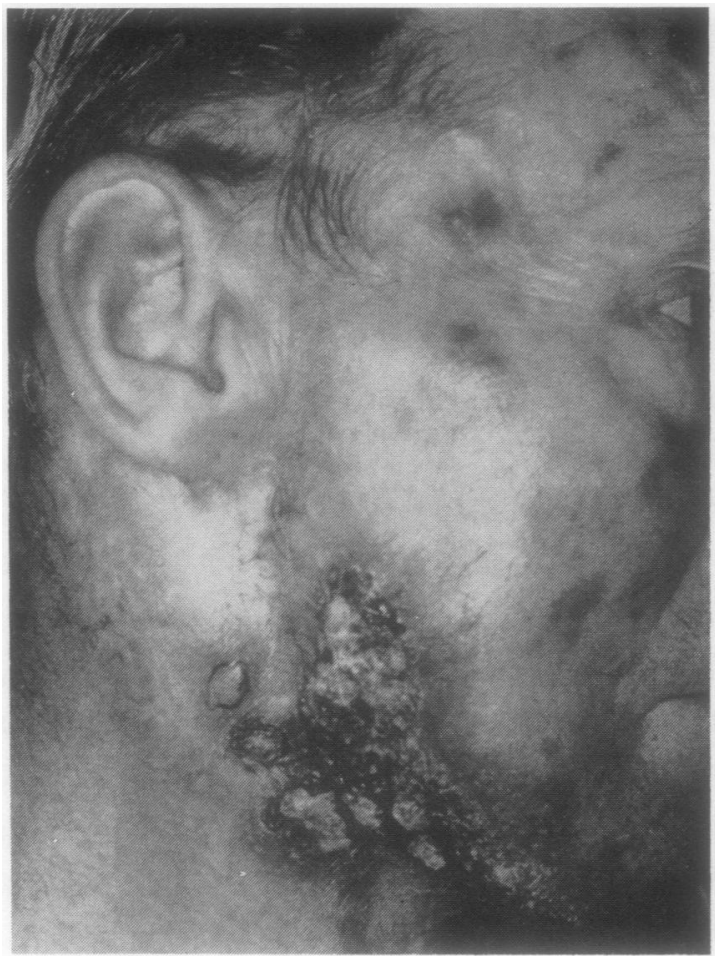

Fig. 1 Ulcerating facial rash and scarring.

at $53 \%$ (normal $0-16 \%$ ). Some components of the complement $\left(\mathrm{CH}_{50}\right.$ and $\left.\mathrm{C} 4\right)$ were decreased. Swabs of the rash grew Staphylococcus aureus.

Multiple biopsy specimens of the rash were taken, all with a similar histological appearance. There was a heavy superficial and deep perivascular infiltrate of lymphocytes, histiocytes, and plasma cells with an occasional eosinophil. The infiltrate was seen to invade the vessel walls, and endothelial cells showed prominent swelling (Fig. 2). It also surrounded small dermal nerves, sweat coils, and pilosebaceous units. Poorly formed aggregates of epithelioid histiocytes in the dermis formed granulomas which included multinucleate giant cells (Fig. 3). These granulomas have close affinity to small dermal blood vessels in some areas. The epidermis was normal, and no organisms were seen.

The rash was initially treated with débridement and oral flucloxacillin, with little effect. The rash continued to extend across the forehead and extensive scarring occurred. Prednisone $60 \mathrm{mg}$ daily was commenced and rapid resolution resulted.

The patient was later readmitted with a fractured femur, which was managed surgically. Postoperatively, he developed palatal ulceration. Biopsies

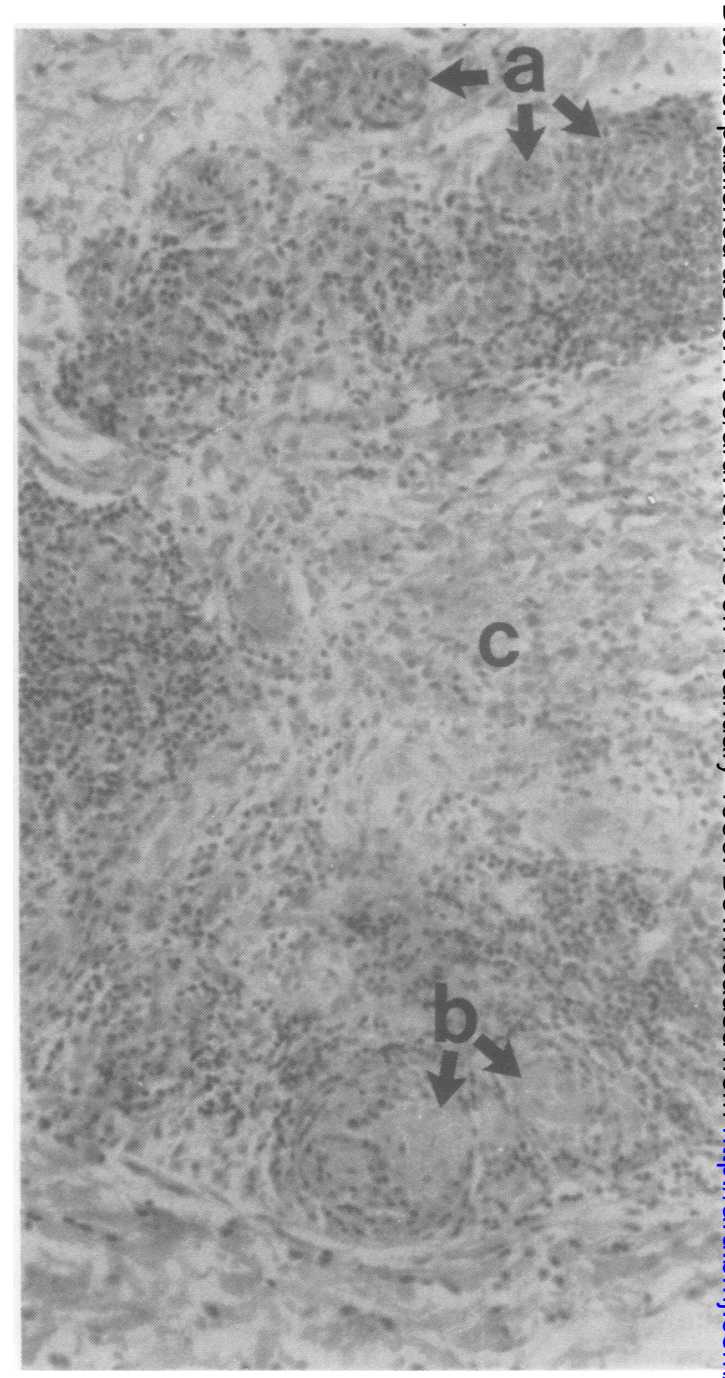

Fig. 2 Mononuclear cells surround and invade small dermal vessels (a) and nerves (b). A large central granulomatous zone is seen (c). (Haematoxylin and eosin, $\frac{D}{0}$ $\times 170)$.

showed an identical granulomatous vasculitis. This again responded to prednisone $60 \mathrm{mg}$ daily.

The patient subsequently developed respiratory insufficiency and died of a perforated gastric ulce The postmortem findings were as follows. The lungs showed prominent interstitial pneumonitis and $\mathrm{fi}_{\overline{0}}$ brosis and extensive areas of eosinophilic necros with surrounding granulomatous reaction and $\mathrm{fP}$ brosis. Rheumatoid nodules were found involvin the visceral pleura and pericardium. There was afl acute infarct of the left temporoparietal region. 


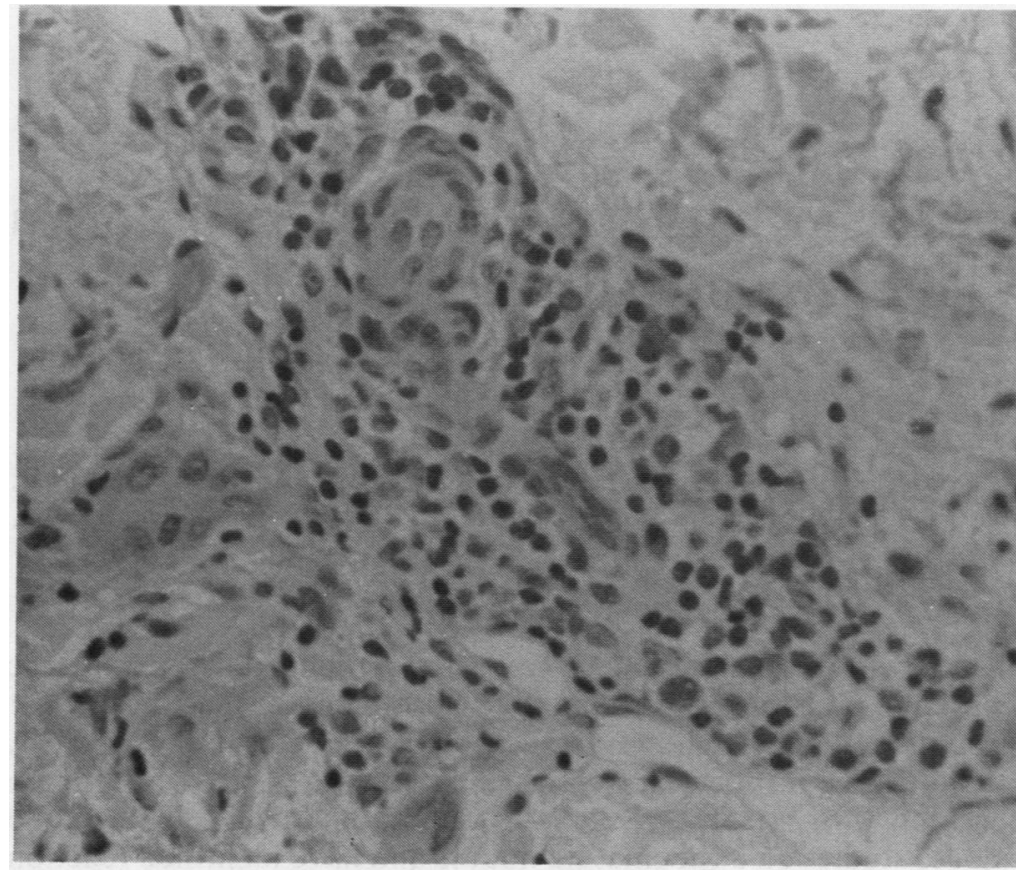

Fig. 3 The dermal capillary shows a granulomatous vasculitis. Epithelioid and multinucleated giant cells are seen at the periphery of the lymphoid infiltrate.

(Haematoxylin and eosin, $\times 400$ ).

\section{Discussion}

The possible causes of our patient's rash were limited, and the diagnosis of granulomatous vasculitis associated with rheumatoid disease was made by exclusion. Infections such as leprosy and syphilis, which may produce a similar histology, were excluded on clinical and serological grounds. There were no drugs that could be implicated. Although the clinical appearance resembled discoid lupus in some respects, particularly the scarring, the histology showed none of the characteristic epidermal features. Similarly, the histological and clinical appearance was distinctly different from that seen in pyoderma gangrenosum in that the infiltrate in our case was of chronic inflammatory cells rather than neutrophils and abscess formation.

Occasional cases of granulomatous vasculitis in seropositive nodular rheumatoid arthritis have been reported. ${ }^{78}$ These differ from ours clinically in that the lesions were always on the lower limbs and scarring was not a feature; and histologically in that they showed prominent nodule formation with necrobiosis and palisading. The authors felt that their cases belonged to a spectrum which included rheumatoid nodules, and which had a vasculitic basis. However, a recent report, ${ }^{9}$ while describing granuloma formation and fibrinoid necrosis in the earlier stages of formation of rheumatoid nodule, was unable to show convincing evidence of vascular involvement.

We feel that our case of granulomatous vasculitis may be an even earlier part of the histological spectrum previously described relating to the evolution of the rheumatoid nodule, where vasculitis is seen before the development of frank necrobiosis and palisading.

\section{References}

1 Soderstrom C W. Cutaneous manifestations of rheumatoid arthritis. Cutis 1979; 24: 553-62.

2 Schmid F R, Cooper N S, Ziff M, et al. Arteritis in rheumatoid arthritis. Am J Med 1961; 30: 56-83.

3 Holt P J A, Davis M G, Saunders K C, Nuki G. Pyoderma gangrenosum. Clinical and laboratory findings in 15 patients with special reference to polyarthritis. Medicine (Baltimore) 1980; 59: 114-33.

4 Laine V A I, Vainio K J. Ulceration of the skin in rheumatoid arthritis. Acta Rheumatol Scand 1979; 8: 151-76.

5 Finan M C, Winkelmann R K. The cutaneous extravascular necrotizing granuloma (Churg-Strauss granuloma) and systemic disease: a review of 27 cases. Medicine (Baltimore) 1983; 62: 142-58.

6 Hurd E R. Extra-articular manifestations of rheumatoid arthritis. Semin Arthritis Rheum 1979; 8: 151-76.

7 Baker R J, Johnson W C, Burgoon C F. Unusual skin lesions of rheumatoid arthritis. Dermatologica 1971; 143: 305-14.

8 Jorizzo J L, Olansky A J, Stanley R J. Superficial ulcerating necrobiosis in rheumatoid arthritis. Arch Dermatol 1982; 118: 255-9.

9 Rasker J J, Kuipers F C. Are rheumatoid nodules caused by vasculitis? A study of 13 early cases. Ann Rheum Dis 1983; 42: 384-8. 